\title{
Erratum to: Conserved gene expression in sperm reservoirs between birds and mammals in response to mating
}

\author{
Mohammad Atikuzzaman', Manuel Alvarez-Rodriguez' ${ }^{1}$ Alejandro Vicente-Carrillo', Martin Johnsson²,
}

Dominic Wright ${ }^{2}$ and Heriberto Rodriguez-Martinez ${ }^{1 *}$

\section{Erratum}

After publication of the original article [1] the authors found that the spelling of author Alejandro VicenteCarrillo's surname was incorrect.

In the original article, the hyphen was missed between Vicente and Carrillo and was incorrectly spelt Vicente Carrillo, when the correct spelling was Vicente-Carrillo.

The original article has been corrected.

\begin{abstract}
Author details
'Department of Clinical and Experimental Medicine, Faculty of Medicine and Health Sciences, Campus HU/US, Developmental Biology, Linköping University, Lasarettsgatan 64/65, Lanken, floor 12, SE-581 85 Linköping, Sweden. ${ }^{2}$ Department of Physics, Chemistry and Biology, Faculty of Science and Engineering, Linköping University, Linköping, Sweden.
\end{abstract}

Received: 3 July 2017 Accepted: 3 July 2017

Published online: 25 July 2017

\section{Reference}

1. Atikuzzaman M, Alvarez-Rodriguez M, Carrillo AV, Johnsson M, Wright $D$,

Rodriguez-Martinez H. Conserved gene expression in sperm reservoirs

between birds and mammals in response to mating. BMC Genomics. 2017;

18:98. doi:10.1186/s12864-017-3488-X.

\footnotetext{
* Correspondence: heriberto.rodriguez-martinez@liu.se

'Department of Clinical and Experimental Medicine, Faculty of Medicine and

Health Sciences, Campus HU/US, Developmental Biology, Linköping

University, Lasarettsgatan 64/65, Lanken, floor 12, SE-581 85 Linköping,

Sweden

Full list of author information is available at the end of the article
} 